\title{
A comparison between the crystal and solution structures of Escherichia coli asparaginase II $^{*}$
}

\author{
Maciej Kozak ${ }^{\bowtie}$ and Stefan Jurga \\ Department of Macromolecular Physics, Faculty of Physics, Adam Mickiewicz University, \\ Poznań, Poland
}

Received: 05 March, 2002; accepted: 25 May, 2002

Key words: asparaginase, small angle X-ray scattering, structure in solution

\begin{abstract}
The small angle X-ray scattering (SAXS) pattern of the homotetrameric asparaginase II from Escherichia coli was measured in solution in conditions resembling those in which its crystal form was obtained and compared with that calculated from the crystallographic model. The radius of gyration measured by SAXS is about 5\% larger and the maximum dimension in the distance distribution function about $12 \%$ larger than the corresponding value calculated from the crystal structure. A comparison of the experimental and calculated distance distribution functions suggests that the overall quaternary structure in the crystal and in solution are similar but that the homotetramer is less compact in solution than in the crystal.
\end{abstract}

Asparaginase II of Escherichia coli (EcAII) is an amidohydrolase which hydrolyses the amide bond in L-asparagine and converts it to L-aspartic acid and ammonia. In native form, the protein is a homotetramer (Fig. 1), consisting of four identical subunits (denoted as A, B, C and D) of 326 amino acids each with a total molecular mass of $138.9 \mathrm{kDa}$. In bacteria, asparaginases with high affinity toward the substrate are found in the periplasm and are termed type II in contrast to type I isoenzymes (cytosolic with lower substrate affinity). Type II enzymes isolated from $E$. coli and Erwinia chrysanthemi (ErA) are successful drugs in the treatment of acute lymphoblastic leukaemia, leukaemic lymphosarcoma and lymphosarcoma (Chakrabarti, 1997).

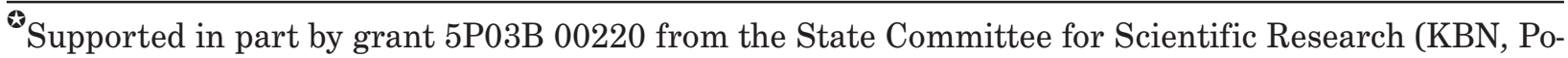
land). M.K. was also awarded by the Foundation for Polish Science 2001. Some of the calculations were performed using the Poznan Supercomputing and Networking Center.

${ }^{\square}$ Corresponding author: Maciej Kozak, Department of Macromolecular Physics, A. Mickiewicz University, Umultowska 85, 61-614 Poznań, Poland; tel: (48 61) 827 3266; fax: (48 61) 825 7758; e-mail: mkozak@amu.edu.pl
}

Abbreviations: EcAII, E. coli asparaginase II; ErA, Erwinia chrysanthemi asparaginase II; SAXS, small angle X-ray scattering. 
When the crystal structure of an enzyme is known it is useful to verify that it also corresponds to the structure in solution since in the crystal the conformation of the molecules is "frozen" and conformationl equilibria, such as domain swapping, are only rarely observed (Janowski et al., 2001). Moreover, the solvation conditions in the crystal usually depart from the physiological ones more than those in solution. Nuclear magnetic resonance (NMR) techniques which give a detailed description of molecular structure in solution are restricted to molecules with molecular masses below $35 \mathrm{kDa}$ and thus not applicable to asparaginase II from $E$. coli. Low resolution structural information can be obtained by small angle X-ray scattering (SAXS) which allows one to examine macromolecular structures ranging in size from small globular proteins (Bu et al., 1998) to ribosomes (Svergun et $a l .$, 1997). The structural parameters obtained by SAXS - radius of gyration $\left(R_{\mathrm{g}}\right)$, pair distance distribution function $(p(\mathrm{R}))$ and maximum dimension $\left(D_{\max }\right)$ - can be directly compared with the corresponding values calculated from crystallographic models.

The crystal structure of asparaginase II from E. coli was determined at $2.3 \AA$ resolution (Swain et al., 1993). Previous X-ray solution scattering studies form (Murthy \& Knox, 1976) allowed the establishing of optimal conditions in which the enzyme exists exclusively as a homotetramer with an almost ideal 222 symmetry. Each asparaginase subunit possesses two $\alpha / \beta$ domains and the active site lies between two $\alpha / \beta$ domains belonging to different monomers. The homotetramer can thus be regarded as a dimer of dimers. A similar situation has only been observed in a very small number of structures, including, e.g., thiamine phosphate-dependent enzymes which may have slightly different structures in the crystal and in solution (Lindqvist et al., 1992; Svergun et al., 2000). It thus seemed useful to compare the structure of asparaginase II from $E$. coli in solution and in the crystal.

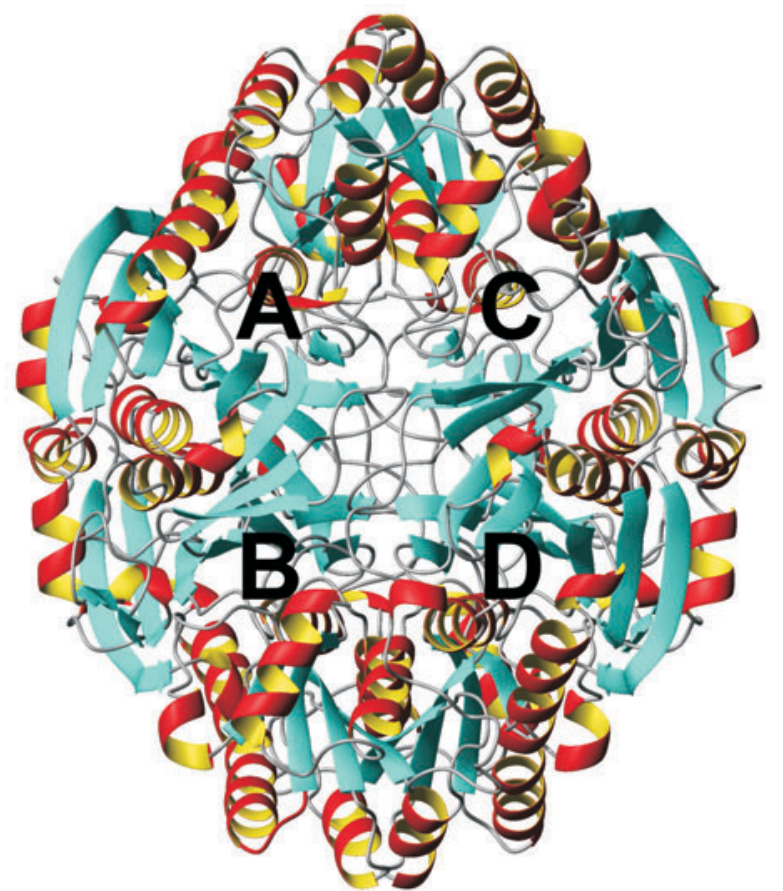

Figure 1. The homotetramer of asparaginase II from $E$. coli.

\section{MATERIAL AND METHODS}

Sample preparation. Lyophilised asparaginase (Sigma) was dissolved in $100 \mathrm{mM}$ Tris buffer, $\mathrm{pH} 8.0$, and $50 \mathrm{mM} \mathrm{NaCl}$, applied to a Sephacryl S-300HR gel filtration column (Pharmacia) and eluted using the same buffer. The purified protein was stored in 95\% ammonium sulphate. Prior to SAXS measurements, the protein suspension was dissolved in 50 $\mathrm{mM}$ sodium acetate, $\mathrm{pH} 4.6$, and $50 \mathrm{mM} \mathrm{NaCl}$ and concentrated by ultrafiltration, using a Centricon 30 (Amicon). The final protein concentration was determined by UV absorption at $280 \mathrm{~nm}\left(\mathrm{~A}_{280}^{0.1 \%}=0.612\right)$.

Small angle $X$-ray scattering. Preliminary small angle X-ray scattering measurements were conducted at room temperature using a NanoSTAR system (Bruker AXS) with pinhole collimation and a two-dimensional detector, mounted on an X-ray tube with copper anode and equipped with crossed Göbel mirrors. The sample-to-detector distance was $650 \mathrm{~mm}$. The exposure time for a single frame was, ap- 
proximately, $15000 \mathrm{~s}$. The intensities were recorded within the range of $0.1<\mathrm{s}<1 \mathrm{~nm}^{-1}$.

The final small angle X-ray scattering data were recorded using a linear gas proportional detector with delay line readout (Boulin et al., 1986; 1988) on the X33 camera (Koch \& Bordas, 1983) of the EMBL on the DORIS storage ring at DESY (Hamburg, Germany). The sample-to-detector distances were 1.4 and $2.9 \mathrm{~m}$. The momentum transfer axis $(\mathrm{s}=$ $4 \pi \sin \theta / \lambda$ with $2 \theta$ the scattering angle and $\lambda$ the X-ray wavelength $(0.15 \mathrm{~nm}))$ was calibrated using the diffraction patterns of turkey tendon collagen and tripalmitin. Samples $(100 \mu \mathrm{l})$ were placed in a $1 \mathrm{~mm}$ thick thermostat $\left(20 \pm 0.1^{\circ} \mathrm{C}\right)$ sample holder with mica windows and the scattering patterns were recorded in twenty $60 \mathrm{~s}$ frames. The protein concentration was $14 \mathrm{mg} / \mathrm{ml}$ (2.9 m camera) or 21 $\mathrm{mg} / \mathrm{ml}$ (1.4 m camera).

Data processing. The data were normalized to the incident beam intensity, corrected for detector response and the scattering of the buffer was subtracted with the programs SAPOKO (Koch \& Svergun, unpublished) and OTOKO (Boulin et al., 1986). The experimental data collected at the lower concentration using the longer camera distance were merged with the data recorded at the higher concentration with the shorter camera to yield a final scattering curve. The theoretical scattering curve for EcAII was evaluated from the crystal structure of the native form (Swain et al., 1993) (PDB entry: 3ECA) and fitted to the experimental scattering data by the program CRYSOL (Svergun et al., 1995). The distance distribution $p(\mathrm{R})$ functions were calculated from the experimental scattering data by the program GNOM - version for Windows NT (Semenyuk \& Svergun, 1991).

\section{RESULTS AND DISCUSSION}

The value of the radius of gyration $\left(R_{\mathrm{g}}=3.19\right.$ $\pm 0.07 \mathrm{~nm}$ ) obtained from a Guinier plot
(Guinier, 1939) in the range $0.02<\mathrm{s}^{2}<$ $0.3 \mathrm{~nm}^{-2}$ (Fig. 2) is in good agreement with

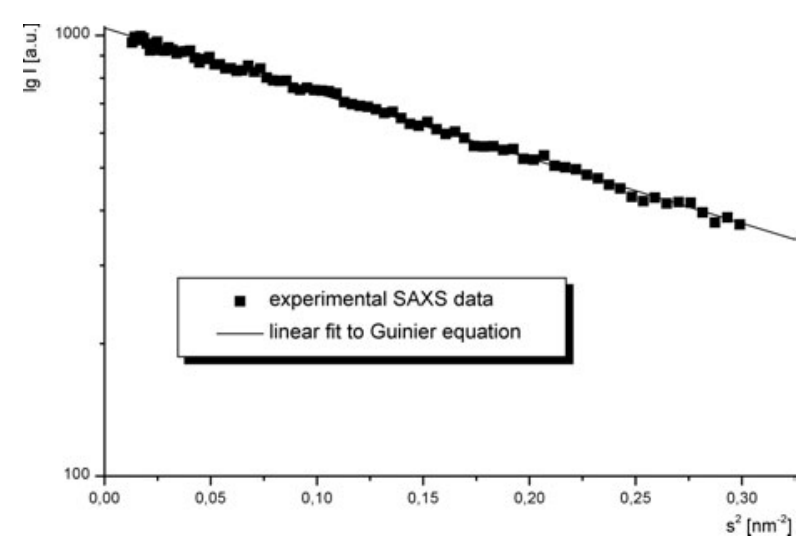

Figure 2. Guinier plot for $E$. coli asparaginase II.

that reported previously for a $1.24 \%$ solution of asparaginase (Murthy \& Knox, 1976). The experimental scattering curve of the native EcAII was compared with that evaluated from the crystal structure (Swain et al., 1993). The best fit (Fig. 3) of the scattering curves $(\chi=$ 1.824) was obtained for the excluded volume $V=192 \mathrm{~nm}^{3}$ and radius of gyration $R_{\mathrm{g}}=3.20$ $\mathrm{nm}$ and $R_{\mathrm{g}}=3.03 \mathrm{~nm}$ calculated for the experimental and the crystallographic data, respectively.

A comparison of the distance distribution functions calculated from the crystal struc-

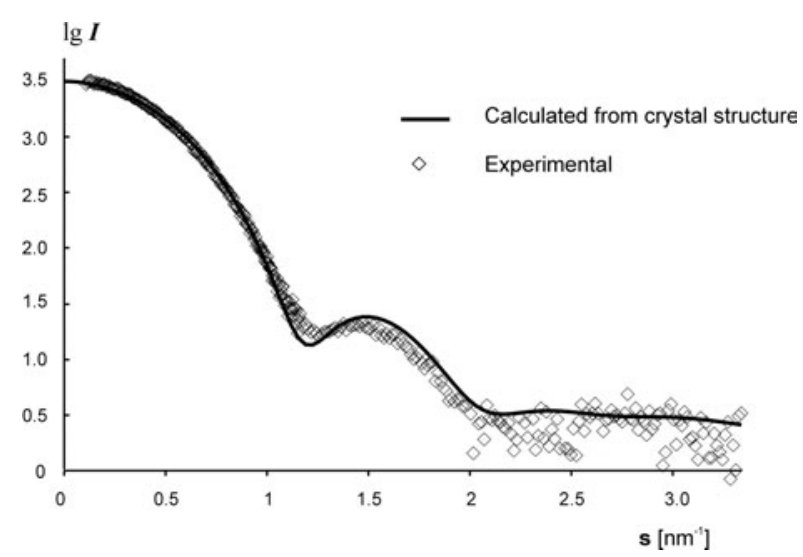

Figure 3. Experimental solution scattering curve (open squares) from native $E$. coli asparaginase II and the scattering from its crystal structure (PDB code: 3ECA) computed with CRYSOL (black line) 
ture and the solution scattering is presented in Fig. 4. The maximum dimension in the crystallographic model is $9.1 \mathrm{~nm}$ and that in solution $10.2 \mathrm{~nm}$, i.e. $12 \%$ higher.

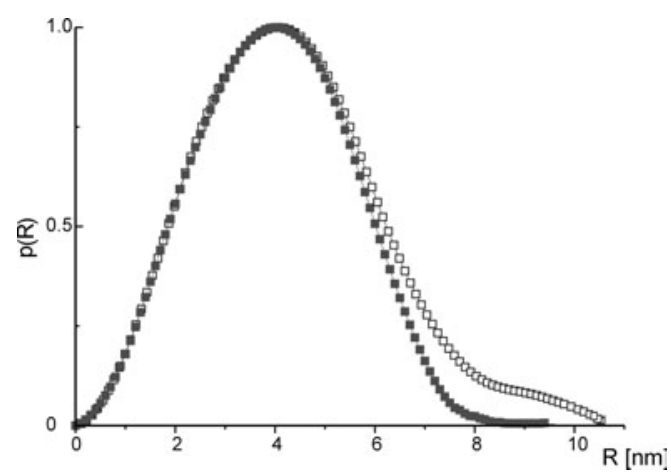

Figure 4. Pair distance distribution functions calculated using solution scattering data (open squares) and crystal structure (black squares)

The systematic deviations in the vicinity of the first subsidiary maximum (Fig. 3) also indicate that the overall structure in solution is less compact than the corresponding crystallographic model and that domain movements, in the case of EcAII - dimers, may have taken place.

In the structure of type II asparaginases, the access to the active centre is closed by a flexible loop (10-40). In an acidic environment favouring product bonding (aspartic acid) the loop assumes a closed conformation and was observed in this form in the majority of structures of EcAII and its mutants. In all these structures also the bonded product was observed, which affected also the stabilisation of the loop. The only EcAII mutant in which this fragment occurs in a well-defined open conformation is Asp90Glu (Kozak et al., 2002). In our experiment we tried to adjust the experimental conditions ( $\mathrm{pH}$, protein concentration, buffer) to be the closest to those in which the polymorphic forms with the loops in the closed conformation were crystallized. That is why we can exclude the effect of the open loop conformation on the value of the gyration radius. Also the resolution of the data recorded ( $\mathrm{s}=3.3 \mathrm{~nm}^{-1}$ ) corresponding to the $\mathrm{d}$-spacing of about $2.1 \mathrm{~nm}$, excludes the effect of local structural changes on the differences observed. Therefore the only explanation of the structural changes noted $\left(R_{\mathrm{g}}\right.$ and $\left.D_{\max }\right)$ can be an expansion of the structure of the whole tetramer in solution.

The enzymatic activity of asparaginase requires that the geometry of its active centre be fully preserved. In the case of EcAII the centre is formed by amino acids of the A and $\mathrm{C}$ and $\mathrm{B}$ and $\mathrm{D}$ subunits, respectively, and the geometry of the active dimers of the $\mathrm{AC}$ and $\mathrm{BD}$ can be assumed to remain unchanged. However, the relative positions of the $\mathrm{AC}$ and $\mathrm{BD}$ active dimers may be altered due to their separation and re-orientation. In the crystalline state, the 222 symmetry remains exact only for asparaginase from Acinetobacter glutaminificans AGA (Lubkowski et al., 1994). In the case of EcAII (Swain et al., 1993) and its mutants (Jaskólski et al., 2001; Kozak \& Jaskólski, 2000; Kozak et al., 2000; Palm et al., 1996) slight deviations from the ideal 222 molecular symmetry, not exceeding $0.1^{\circ}$, were observed. In solution, larger deviations may occur which do not significantly disturb the geometry of the active centres.

\section{R E F E R E N C E S}

Boulin C, Kempf R, Koch MHJ, McLaughlin S. (1986) Data acquisition systems for linear and area X-ray detectors using delay line readout. Nucl Instrum Methods.; A249: 399-407.

Boulin CJ, Kempf R, Gabriel A, Koch MHJ. (1988) Data acquisition systems for linear and area X-ray detectors using delay line readout. Nucl Instrum Methods Phys Res.; A269: 312-20.

Bu Z, Koide S, Engelman DM. (1998) A solution SAXS study of Borrelia burgdorferi OspA a protein containing a single-layer $\beta$-sheet. Protein Sci.; 7: 2681-3.

Chakrabarti R. (1997) L-Asparaginase perspectives on the mechanisms of action and resis- 
tance. Int J Pediatr Hematol Oncol.; 4: $597-611$.

Guinier A. (1939) La diffraction des rayons X aux trés petits angles; application à l'étude de phénomènes ultramicroscopiques. Ann Phys.; 12: 166-237.

Janowski R, Kozak M, Jankowska E, Grzonka Z, Grubb A, Abrahamson M, Jaskólski M. (2001) Human cystatin $\mathrm{C}$, an amyloidogenic protein, dimerizes through three-dimensional domain swapping. Nature Struc Biol.; 8: 316-20.

Jaskólski M, Kozak M, Lubkowski J, Palm G, Wlodawer A. (2001) Structures of two highly homologous bacterial L-asparaginases: a case of enantiomorphic space groups. Acta Cryst.; D57: $369-77$.

Koch MHJ, Bordas J. (1983) X-Ray diffraction and scattering on disordered systems using synchrotron radiation. Nucl Instrum Methods.; 208: 461-9.

Kozak M, Jaskólski M. (2000) Crystallization and preliminary crystallographic studies of a new crystal form of Escherichia coli L-asparaginase II (S58A mutant) Acta Cryst.; D56: $509-11$.

Kozak M, Jaskólski M, Röhm KH. (2000) Preliminary crystallographic studies of Y25F mutant of periplasmic Escherichia coli L-asparaginase Acta Biochim Polon.; 47: 807-14.

Kozak M, Borek D, Janowski R, Jaskólski M. (2002) Crystallization and preliminary crystallographic studies of five crystal forms of Escherichia coli L-asparaginase II (Asp90Glu mutant) Acta Cryst.; D58: 130-2.

Lindqvist Y, Schneider G, Ermler U, Sundström M. (1992) Three-dimensional structure of transketolase, a thiamine diphosphate-dependent enzyme, at $2.5 \AA$ resolution. EMBO J.; 11: 2373-9.
Lubkowski J, Wlodawer A, Housset D, Weber IT, Ammon HL, Murphy KC, Swain AL. (1994) Refined crystal structure of Acinebacter glutaminaficans glutaminase-asparaginase. Acta Cryst.; D50, 826-32.

Murthy NS, Knox JR. (1976) Small-angle X-ray scattering studies of Escherichia coli L-asparaginase. J Mol Biol.; 30: 567-75.

Palm GJ, Lubkowski J, Derst C, Schleper S, Rohm KH, Wlodawer A. (1996) A covalently bound catalytic intermediate in Escherichia coli asparaginase: crystal structure of a Thr-89-Val mutant. FEBS Lett.; 390: 211-6.

Semenyuk AV, Svergun DI. (1991) GNOM - A program package for small-angle scattering data processing. J Appl Cryst.; 24: 537-40.

Svergun DI, Barberato D, Koch MHJ. (1995) CRYSOL - a program to evaluate X-ray solution scattering of biological macromolecules from atomic coordinates $J$ Appl Cryst.; 28: $768-73$.

Svergun DI, Burkhardt N, Skov Pedersen J, Koch MHJ, Volkov VV, Kozin MB, Meervink W, Stuhrmann HB, Diedrich G, Nierhaus KH. (1997) Solution scattering structural analysis of the $70 \mathrm{~S}$ Escherichia coli ribosome by contrast variation. $J$ Mol Biol.; 271: 588-601, 602-18.

Svergun DI, Petoukhov MV, Koch MHJ, König S. (2000) Crystal versus solution structures of thiamine diphosphate-dependent enzymes. J Biol Chem.; 275: 297-302.

Swain AL, Jaskólski M, Housset D, Rao JKM, Wlodawer A. (1993) Crystal structure of Escherichia coli L-asparaginase, an enzyme used in cancer therapy. Proc Natl Acad Sci $U S$ A.; 90: 1472-8. 